\title{
INABILITY OF VIRAL SUPERANTIGENS TO INDUCE CD4-MEDIATED ISLET TRANSPLANT REJECTION
}

Peter Ciechanowski

Department of Biological Sciences (Immunology), University of Alberta

\section{Abstract}

Superantigens have the ability to bypass the specific interactions of the MHC class II and T-cell receptor by binding outside of the peptide binding region and onto the V $\beta$ chain. This ability allows superantigens to stimulate a wide array of T-cell populations, irrespective of T-cell receptor (TCR) specificity. Research on bacterial and viral superantigens have demonstrated various outcomes ranging from superantigen dependent cellular cytoxicity (SDCC), rheumatoid arthritis, to superantigen stimulated T-cell clonal deletion and anergy. Due to its ability to proliferate a large population of T-cells, this paper asks whether superantigens have a role in islet transplant rejection. We used transgenic V 36 TCR mice specific for male ' $\mathrm{H}-\mathrm{Y}$ ' antigen as recipients to islet transplants. Donors comprised mice expressing endogenous superantigen specific for the V $\beta 6$ chain. Transplantation of these donor islets did not induce rejection. Recipients were also primed with ' $\mathrm{H}-\mathrm{Y}$ ' antigen to induce a CD4 effector memory T-cell population prior to islet transplantation. Even with primed recipients, donor islet transplants did not induce rejection by recipient transgenic mice.

\section{Introduction}

The immune system is an important evolutionary mechanism that provides humans the capability of fighting infectious agents such as bacteria and viruses (1). The immune system involves the use of particular sophisticated cells that perform two main duties: find and destroy the infectious agent while limiting damage to the host (2). While providing a great advantage over immunodeficient humans who are unable to protect themselves from foreign agents, the immune system does have drawbacks.

The immune system plays a major role in causing hypersensitivity and allergic reactions (3), as well as autoimmunity $(4,5)$. In relation to transplants, the host's immune system is a major player in determining the rejection or acceptance of the transplant. One would think that tissue or organ transplants between two individuals would not be a problem if both belong to the same species. But there are genetic variations between individuals that cause the recipient to recognize the genetically disparate molecules as foreign (6). As the immune system recognizes foreign antigens as dangerous to the host, the immune system detects the donor's organ or tissue as an infectious agent. Subsequently, this results in immunological transplant rejection (7).

The immune system is divided between innate and adaptive compartments. Although performing certain specific actions, it is now generally understood that these are not separate compartments. Both compartments communicate and function together and thus there is some overlap between the two (8). An important set of cells comprising the adaptive immune system is the T-cell.

\section{The Major Histocompatibility Complex}

The T-cell carries a T-cell receptor that is specific towards a particular foreign antigen. T-cell receptors (TCRs) interact with processed peptides presented on either the major histocompatibility complex (MHC) class I or class II molecules (9). The MHCs are highly polymorphic proteins that aid in presenting foreign peptides to the $\alpha \beta$ receptors of the TCR (10).

Active in almost all cell types, the MHC class I antigen presentation pathway involves presenting peptides at the cell surface. The peptides derive from the proteins synthesized in the cell at any time and thus enable CD8 T-cells to detect and kill any infected cell. The MHC class II presentation pathway is an important component of 'professional' antigen-presenting cells (APCs), such as B-cells (another adaptive immune system cell type) and macrophages. The peptides derive from exogenous proteins via endosomal compartments. The APCs present these exogenous peptides to CD4 T-cells, which then causes the CD4 T-cells to perform mechanism such as phagocytosis and macropinocytosis (11).

Because the MHC is highly polymorphic, both classes have the ability to bind and present a wide diversity of peptides. Through MHC restriction, TCRs on CD8 and CD4 $\mathrm{T}$-cells are restricted to recognizing peptides on host $\mathrm{MHC}$ molecules (12). Nonetheless, there are some TCRs that have an ability to bind to foreign MHC molecules with or without loaded peptides (13). Along with MHC restriction, the clonal selection theory argues that each T-cell expresses specificity to only one particular antigen (10).

\section{Transplant Rejection: Indirect and Direct Presentation}

Type- 1 diabetes is an autoimmune disease produced by $\mathrm{T}$ lymphocytes that selectively destruct insulinproducing pancreatic $\beta$-cells (14). A person's susceptibility and resistance to autoimmune disorders is mostly associated with polymorphisms of genes of the MHC. Islet transplantation has been used to treat type-1 diabetics, but its propensity for rejection has made it difficult to be a very successful treatment option.

There are two main pathways in the induction of transplant rejection. The first is 'direct' recognition where donor antigen presenting cells (APCs) stimulate host T-cells. The second is 'indirect' recognition where host APCs stimulate host T-cells (15). There is no concrete evidence which pathway is the most dominant in a given situation relating to a particular islet transplantation. On the other hand, observations have been made for each pathway suggesting their dominant role in islet transplant rejection.

There are three observations that argue 'direct' recognition is a major pathway in allograft rejection. First, in a primary allogeneic mixed lymphocyte reaction (MLR), direct stimulation is very prominent. Second, allograft 
survival may be sometimes prolonged with donor APC depletion. Third, donor MHCs are more important the minor antigens in producing graft rejection (15). Likewise, there are a couple of arguments explaining the importance of an 'indirect' response. First, this pathway alone may induce rejection. Second, in some instances where rejection involves both pathways, the 'indirect' pathway occurs much more rapidly than the 'direct' pathway (16). These two pathways, which involve two different kinds of APCs (one from the host and the other form the donor) is a fundamental feature of graft rejection that distinguishes it from other immune responses (16). Understanding the basis of transplant rejection will be important in understanding the rationale for choosing experimental models for evaluating the role of Superantigens in transplant rejection.

\section{Introduction to Superantigens}

A typical antigen has the capability to interact with 1 in $10^{4}$ to 1 in $10^{6} \mathrm{~T}$ cells. Normal antigens must be presented in a major histocompatibily complec $(\mathrm{MHC})$-restricted fashion as well as interact with a specific TCR. Superantigens are a class of immunostimulatory antigens of bacterial and viral origin (16). These are special antigens that do not require recognition by a specific TCR $\alpha / \beta$ heterodimer (16). Instead, the main requirement for recognition is superantigen binding $V \beta$ chain region of the TCR outside of the antigen binding site (17). As well, superantigens are presented on the MHC Class II molecule from an antigen presenting cell (APC). These particular antigens essentially act as a wedge between the TCR $\beta$ chain and the MHC class II $\alpha$ chain. Binding outside of the TCR $\alpha / \beta$ heterodimer means that there is a bypass from the normal mechanism for T-cell triggering by specific peptide/MHC complexes (18). Thus, superantigens have the capability of interacting with thirty percent of T-cells. This propensity for wide scale interaction with T-cells has given these special antigens several descriptors, mainly as minor histocompatibiliy antigens and mitogens. (19).

Superantigens gained notoriety in the first place due to their ability to produce superantigen dependent mediated cellular cytoxicity (SDCC). SDCC inevitably leads to toxic shock syndrome (TSS), which is a life-threatening intoxication produced by staphylococcal and streptococcal pyrogenic toxins (17). TSS is life threatening due to a massive cytokine release (e.g. TNF $\beta$, IL-2, and gamma interferon) leading to a variety of symptoms such as hypotension and multiorgan dysfunction (17). Staphylococcal enterotoxins are also associated with food poisoning and scaled skin syndrome due to proliferation of polyclonal T-cells (20).

Besides fates such as anergy, clonal deletion, or toxic shock syndrome, research is starting to investigate superantigen effects in autoimmune diseases. A human endogenous retrovirus HERV-K18 is believed to produce superantigens that play a role in developing rheumatoid arthritis (17). There has also been a link between an endogenous human retrovirus responsible for producing superantigens and primary biliary cirrhosis in recipients of liver transplants (21).

\section{Do Superantigens Play a Role in Islet Transplant Rejection?}

This research project addresses whether superantigens have the capability of inducing transplant rejection. To study the role of superantigens, this research focuses on the retrovirus called the 'Mouse Mammary Tumor Virus' (MMTV). MMTV can exist in two forms: germline integrated (endogenous MMTV) or as milk-transmitted infectious virus (exogenous MMTV) (22). All laboratory mouse strains contain endogenous MMTV, most of which have lost their infectious character of milk transmission (22).

In this experiment, transgenic mouse strains are used that carry only a specific $T$-cell receptor and V $\beta$ chain. As well, the donor will carry a known endogenous superantigen that has the capability to recognize the recipient's specific $V \beta$ chain. Using transgenic mouse strains eliminates variables that may induce transplant rejection other than a superantigen. Since the recipient $\mathrm{T}$-cell receptor only recognizes a specific antigen, then donor mismatching of the major histocompatibility complex cannot be a factor in transplant rejection. Through islet transplantation that carries an endogenous superantigen, if rejection does occur then it will be due to indirect presentation. Relating to the literature presented in the previous section on its role in autoimmune diseases, I expect the MMTV superantigen to produce a T-cell proliferative response that will lead to islet transplant rejection via the indirect presentation pathway.

\section{Materials and Methods \\ Mice}

Mice used in these experiments were: DBA/2NCR, B10 - [Tg]Marilyn - [KO] RAG2 - [KO] PD-1, B10 - [Tg]Marilyn [KO] RAG2, B6, BALB/c, and OT-2 mice. All mice received from either the $\mathrm{NCl}$-Frederick Cancer Research Institute or the Health Sciences Laboratory Animal Services.

\section{Media}

Culture media: $437.5 \mathrm{ml}$ IMDM (with NAHCO3), 50.0ml Fetal Bovine Serum (FBS), 5.0ml Penicillin/Streptomycin, $5.0 \mathrm{ml}$ Glutamine, $2.5 \mathrm{ml}$ Gentamycin, and $1.92 \mu \mathrm{l} \mathrm{beta-}$ mercaptoethanol. All ingredients must be added into an autoclaved bottle under a laminar flow hood with the use of a filter sterilizer.

Assay media: 487ml IMDM (with $\mathrm{NaHCO}$ ) and $13 \mathrm{ml}$ FBS into an autoclaved bottle under a laminar flowhood.

PBS $/ 0.1 \%$ BSA: $100 \mathrm{ml}$ PBS and $0.1 \mathrm{ml}$ Bovine Serum Albumin (BSA).

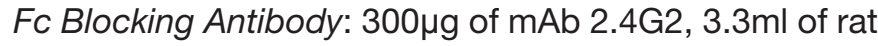
serum, $3.3 \mathrm{ml}$ of hamster serum, and $3.3 \mathrm{ml}$ mouse serum.

\section{Antibodies for Lymphocyte Staining}

Antibodies were diluted in $1 \%$ BSA, which was made from diluting $10 \%$ dialyzed BSA with PBS. Antibodies were diluted according to the appropriate concentration.

\section{Carboxyfluorescein Succinimidyl Ester (CFSE) Staining}

Took out the spleens from responder (cells tested for T-cell proliferation) and stimulator (cells used to induce T-cell proliferation). Responder spleens were placed in $\mathrm{PBS} / 0.1 \% \mathrm{BSA}$ while stimulator spleens went into 
culture media in separate $50 \mathrm{ml}$ conicals. All conicals were set in ice for the remainder of the experiment. Using a hemacytometer, $10 \mu \mathrm{l}$ was taken to count number of responder and stimulator cells. Responder cells were adjusted to a cell concentration range of $10-20 \times 10^{6}$ cells $/ \mathrm{ml}$ to make a volume of $10 \mathrm{ml}$. After setting the new concentration range, $1 \mathrm{ml}$ of responder cells were set aside to comprise the unlabelled CFSE responder cells. The unlabelled responder cells were set to a concentration $1 \times 10^{6} \mathrm{cells} / \mathrm{ml}$ in culture media. Simulator cells were set to a concentration of $3 \times 10^{6}$ cells $/ \mathrm{ml}$. Responder cells for labeling had $0.5 \mathrm{mM}$ CFSE added and mixed to $10 \mathrm{ml}$ of responder cell suspension. CFSE labeled responder cells incubated for 10 minutes at $37^{\circ} \mathrm{C}$. Adding $0.5 \mathrm{ml}$ FBS to the $10 \mathrm{ml}$ responder cell suspension quenched CFSE staining, which was then followed by 5 minutes incubation on ice. After incubation PBS/0.1\% BSA was added to the top of the tube and centrifuged $\left(4^{\circ} \mathrm{C}, 1200\right.$ RPM for 10 minutes). Cells were washed twice, with the last wash being with PBS. Labeled responder cells were FACS analyzed to confirm CFSE staining. After confirmed labeling, responder cells were counted once again with the hemacytometer and adjusted to a concentration of $1 \times 10^{6}$ cells $/ \mathrm{ml}$ with culture media. Stimulator mice were then irradiated (@1500 RADS) 1:20 seconds with the irradiator (irradiator manual was referred in order to set the correct time in relation to the decay factor). Culture wells were set up by producing a maximal volume of $2 \mathrm{ml}$ for each well. With the appropriate stimulators and responders, $1 \mathrm{ml}$ of each was added to the appropriate wells. Positive control for responder cells involved adding $1 \mathrm{ml}$ of $5 \mu \mathrm{g}$ Concanavalin A (ConA). Wells with no stimulator added had $1 \mathrm{ml}$ of culture media added instead. Culture wells incubated for 4 days at $37^{\circ} \mathrm{C}$, which were then FACS analyzed under the appropriate markers.

\section{Flow Cytometry}

The volume of Blocking Antibody, cells to be stained, and antibody were always the same to each other. Cell volumes of $25 \mu \mathrm{l}$ were placed in FACS tubes. Blocking Antibody $(25 \mu \mathrm{l})$ was then added to each FACS tube and subsequently vortexed and incubated at room temperature for 5 minutes. Then, $25 \mu$ l of diluted antibody was added, vortexed, and placed in a fridge for 15 minutes. Cells were washed with $3 \mathrm{ml}$ of PBS. After centrifugation, supernatant was dumped. Pellet was re-suspended in $300 \mu$ and vortexed. For peripheral blood, $20 \mu \mathrm{l}$ of heparin was added to $2 \mathrm{ml}$ conical tubes where about 15 to 20 drops of peripheral blood was collected and added to the $2 \mathrm{ml}$ conical tube. After, $30 \mu \mathrm{l}$ of mixed heparin and blood is placed into a FACS tube. $30 \mu$ l of Blocking Antibody and diluted antibody were added, respectively. After 15 minutes in the fridge, $3 \mathrm{ml} \mathrm{RBC}$ lysis buffer is added to each FACS tube and centrifuged ( $4^{\circ} \mathrm{C}, 1200 \mathrm{RPM}, 10$ minutes). After centrifugation the supernatant was dumped and the pellet re-suspended in $300 \mu \mathrm{l}$. FACS dot plots were analyzed using CellQuest.

\section{Histology}

The 'Heritage Research and Innovation Facility' laboratory performed histology of mice kidney capsules.
Kidney capsules were stained with hematoxylin and eosin.

\section{Islet Transplantation:}

A concentration of $195 \mu \mathrm{g} / \mathrm{kg}$ of streptozotocin was added to recipient mice through intraperitoneal injection three days prior to the day of transplantation. A 'ONE TOUCH ULTRA 2' blood glucose reader with a calibration code of ' 25 ' monitored blood glucose levels. Two successive readings of greater than $15 \mathrm{mmol} / \mathrm{L}$ from the glucose reader confirmed the recipient mouse as diabetic. On the day of transplantation, two donor mice were used for one recipient (ratio of 2:1). After transplantation, blood glucose readings were taken to confirm success of islet transplantation (a reading of less than $10 \mathrm{mmol} / \mathrm{L}$ ). After confirmation of islet transplant, blood glucose readings were taken periodically. FACS analysis of recipient peripheral blood was taken after 10 and 16 days post-transplantation.

\section{Priming Recipient Mice:}

B6 male splenocytes were mixed with PBS. Splenocytes were counted with a hemacytometer and cell concentration was adjusted to $12 \times 10^{6}$ cells $/ 1 \mathrm{ml}$. Recipient mice were intraperitoneal injected with $0.250 \mathrm{ml}$ of $\mathrm{B} 6$ male splenocytes. Eleven days after injection, peripheral blood of recipient mice was analyzed under FACS analysis to confirm successful priming. After confirmation, primed recipient mice received islet transplants.

\section{Results}

DBA-2 and BALB/C Superantigens Are Capable of Stimulating Monoclonal Naïve T-cell Populations:

DBA-2 mouse contains an endogenous MMTV superantigen that can recognize and stimulate T-cells with a V $\beta 6$ T-cell receptor chain. Marilyn mice contain a monoclonal T-cell population as well as the V $\beta 6$ T-cell receptor chain. Before performing any experiments with donor DBA-2 islet cells and recipient Marilyn, it must first be established that DBA-2 superantigen has the capability of stimulating the Marilyn monoclonal T-cell population. OT-2 mice also have a monoclonal T-cell population that can recognize only Ovalbumin (OVA) as well as a VB5 T-cell receptor chain. BALB/c mice carry an endogenous MMTV strain that can recognize the $V \beta 5$ chain, so the BALB/c OT-2 experimental model was used as a comparison to the DBA-2 - Marilyn model. Because studies have shown that some superantigens may cause clonal anergy, deletion, or both after T-cell stimulation, Marilyn PD-1 KO mice are used. A mouse deficient in PD-1 will have T-cells that will not have inhibition of activation upon stimulation and will proliferate at much higher rates than wild type Marilyn.

Female Marilyn and OT-2 mouse splenocytes were mixed with irradiated splenocytes of different stimulator groups. Female Marilyn responder splenocytes were mixed with either: B6 female (no antigen), B6 male (male ' $\mathrm{H}-\mathrm{Y}$ ' antigen) or DBA-2 female (superantigen) stimulators. OT-2 responder splenocytes were mixed with either: B6 (no antigen), OVA (antigen), or BALB/c (superantigen). Controls for both experimental models was adding no stimulators (negative control) and adding ConA (positive control). ConA is a mitogen that binds to T-cell receptors and thus 
stimulates proliferation.

This 'in vitro' experiment showed that responder T-cells from both female Marilyn PD-1 KO and OT-2 mice were recognized by their respective stimulator superantigens: DBA-2 and BALB/c, respectively. ConA stimulator showed the highest $\mathrm{T}$-cell proliferation rates for both responder mice. Proliferation rates for antigen stimulated were similar in comparison to both responders, with $22 \%$ for B6 male and $28 \%$ for OVA female. On the other hand, proliferation rates for superantigens varied greatly between the two responders. With DBA-2, the proliferation rate was $47 \%$ while for BALB/c it was $8.15 \%$. This showed that different superantigens recognizing different $V \beta$-chain TCRs have different capabilities in stimulating monoclonal T-cell proliferation.

A problem with performing the 'in vitro' experiment was that absolute numbers of gated CD90.2 ${ }^{\mathrm{HI}} \mathrm{CD} 4^{\mathrm{HI}} \mathrm{T}$-cells varied greatly. An example was with $\mathrm{CD} 90.2^{\mathrm{HI}} \mathrm{CD} 4^{\mathrm{HI}} \mathrm{T}$-cells gated for experimental group with no stimulators added. For Marilyn PD-1 KO, there were sixty-two gated events while for OT-2 there were 934 gated events. As well, I performed this same experiment with Marilyn mice and there was little to no lymphocytes present in all experimental groups. This variability in T-cell population may be attributed to steps in the experimental process, which may have resulted in loss to T-cell numbers.

First, I used the hemacytometer in counting splenocytes for adjusting appropriate cell concentrations. This counting process accounts for all cells (except RBCs) and not only T-cell populations. It was possible that I did not accurately adjust splenocyte populations to the correct concentrations and this might have overall affected T-cell population concentration numbers.
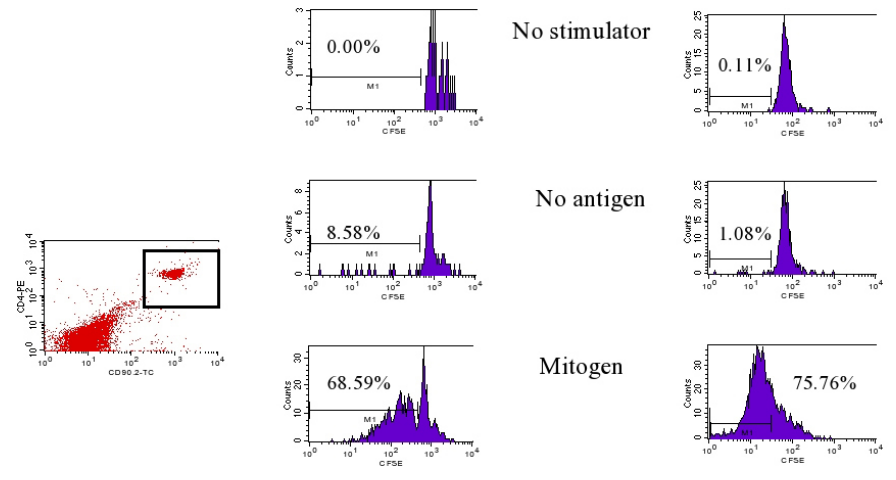

No antigen

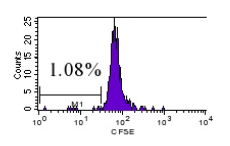

Mitogen
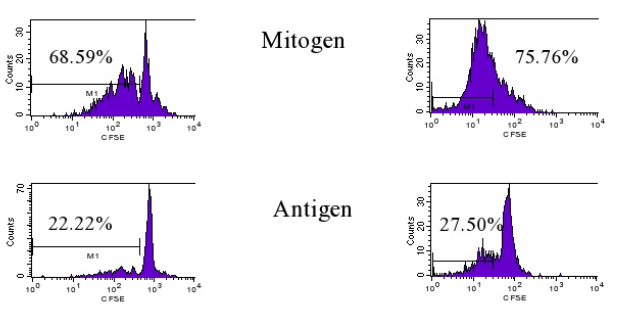

Antigen
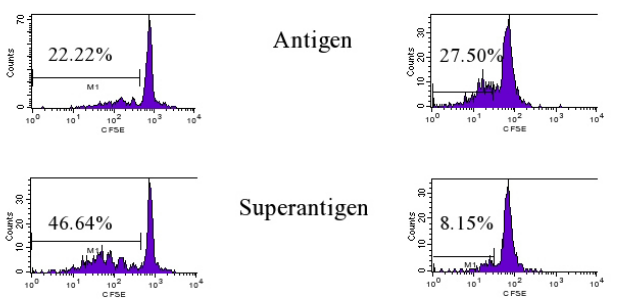

Superantigen

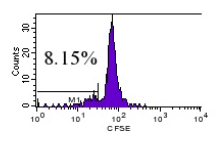

Figure 1. T-cell proliferation histogram analysis of $1 \times 10^{6} \mathrm{CFSE}$ labeled responder splenocytes with $3 \times 10^{6}$ irradiated stimulator splenocytes. CFSE was added with a concentration of $0.5 \mathrm{mM}$ and analysis was analyzed after 4 days of incubation at $37^{\circ} \mathrm{C}$. Data was gated on $\mathrm{TCR}^{\mathrm{HI}} \mathrm{CD} 90.2^{\mathrm{HI}}$ cell populations through dot plot analysis. Marilyn PD-1 KO female and OT-2 responder female splenocytes were used on the left and right columns, respectively. No stimulators contained only responder splenocytes. No antigen stimulators were B6 female (left) and B6 male (right). Antigen stimulators contained B6 male (right) and OVA female (left). Superantigen stimulators contained DBA-2 female (right) and BALB/c female (left).
Second, I used a vacuum with a small pipet to remove supernatants after centrifuging and I might have involuntarily removed a significant portion of the T-cell population. These two factors (incorrect concentration adjustments and incorrect removal of supernatant) might have contributed to adding less than $1 \times 10^{6}$ responder cells.

From the in vitro experiment, it was shown that superantigens have the ability to stimulate monoclonal T-cell populations to proliferate. This being demonstrated, the next process was to study whether these superantigen
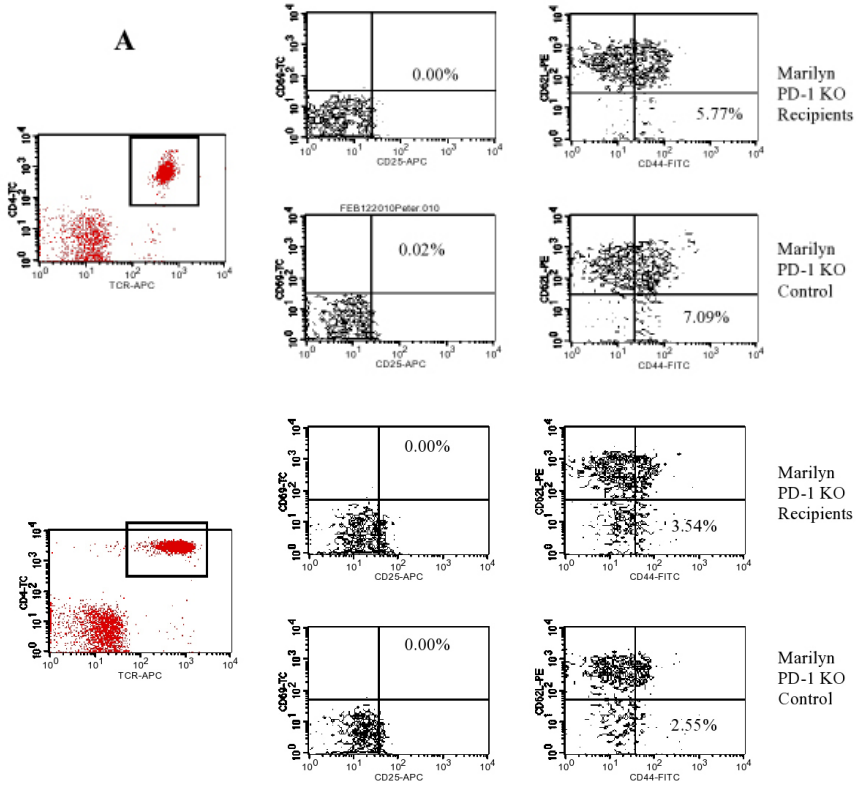
Recipients
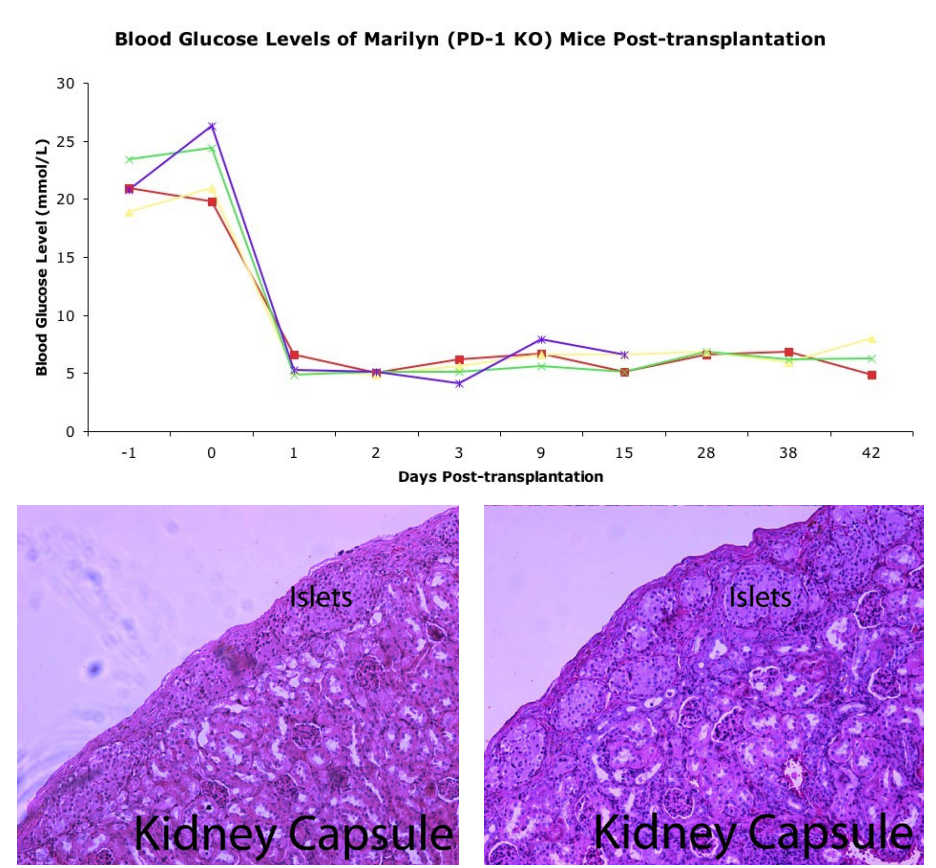

Figure 2. Marilyn PD-1 KO female recipients $(n=4)$ received DBA-2 female islet transplants and were monitored for rejection. $A$, Dot plot analysis for $\mathrm{CD} 64^{\mathrm{HI}}$ $\mathrm{CD}^{2} 5^{\mathrm{HI}}$ and $\mathrm{CD} 62 \mathrm{~L}^{\mathrm{LO}} \mathrm{CD} 44^{\mathrm{HI}}$ cells measured 10 days post-islet transplantation. Both dot plots were gated on TCR ${ }^{\mathrm{HI}} \mathrm{CD}^{\mathrm{HI}}$. Marilyn PD-1 KO female recipients $(\mathrm{n}=4)$ located above and Marilyn PD-1 KO female control located below $(\mathrm{n}=4)$. $B$, Dot plot analysis for CD64 ${ }^{\mathrm{HI}} \mathrm{CD} 25^{\mathrm{HI}}$ and $\mathrm{CD} 62 \mathrm{~L}^{\mathrm{LO}} \mathrm{CD} 44^{\mathrm{HI}}$ cells measured 16 days post-islet transplantation. Both dot plots were gated on TCR ${ }^{\mathrm{HI}} \mathrm{CD} 4^{\mathrm{HI}}$. Marilyn PD-1 $\mathrm{KO}$ recipients $(\mathrm{n}=4)$ located above and Marilyn PD-1 KO control located below $(\mathrm{n}=3)$. C, Blood glucose levels measured of recipient Marilyn PD-1 KO mice $(\mathrm{n}=4) . D$, Hematoxylin and Eosin staining of kidney capsules of recipient Marilyn PD-1 KO female mice $(n=3) 42$ days post-transplantation. 
stimulated monoclonal T-cell populations were capable of causing islet transplant rejection.

Recipient Marilyn PD-1 KO mice received DBA-2 female islet transplants after becoming streptozocin-induced diabetic. Two DBA-2 donors were added for every recipient mouse.

Dot plot analysis of recipient Marilyn PD-1 KO mice showed no comparable difference of activation markers (CD69 $\left.{ }^{\mathrm{HI}} \mathrm{CD}^{2} 5^{\mathrm{HI}}\right)$ for gated $\mathrm{TCR}^{\mathrm{HI}} \mathrm{CD}^{\mathrm{HI}}$ cells for both 10 and 16 days post-transplantation. Population percentage for CD62L ${ }^{\mathrm{LO}} \mathrm{CD}_{4} 4^{\mathrm{HI}}$ in both 10 and 16 days posttransplantation did not show any marked differences between the experimental and control group. Blood glucose readings post-transplantation showed that that recipient mice did not become diabetic, as they did not exceed two consecutive readings greater than $15 \mathrm{mmol} / \mathrm{L}$. Histology of kidney capsules stained with hematoxylin and eosin did not show any presence of lymphocyte infiltration.

Although in vitro analysis showed that superantigen was capable of stimulating a naïve monoclonal T-cell population, DBA-2 superantigen does not induce recipient immune rejection of islet transplants. The next process would be to examine if a recipient with a primed monoclonal T-cell population may induce islet transplant rejection.

\section{Priming Recipient Marilyn and Marilyn PD-1 KO Mice}

Since it was not known what fate naïve T-cells would have after stimulation by superantigens, B6 male carrying ' $\mathrm{H}-\mathrm{Y}$ ' antigen was used in the priming process. Approximately $3 \times 10^{6}$ splenocytes per $0.250 \mathrm{ml}$ were injected into each female Marilyn and Marilyn PD-1 KO recipient mouse via IP injection. After 11 days post-B6 male splenocyte injection, female Marilyn and Marilyn PD-1 KO mice were analyzed through flow cytometry to detect any presence of effector memory T-cells (CD62L LO CD44 H').

Marilyn mice injected with B6 male splenocytes showed an effector memory T-cell population percentage of $1.33 \%$, $0.82 \%$, and $0.69 \%$, respectively. These percentages were higher than the control Marilyn, which was $0.10 \%$. Likewise, B6 male splenocyte injected Marilyn PD-1 KO female mice showed a percentage of $2.68 \%$, while control female Marilyn PD-1 KO had a percentage of $0.03 \%$.

One difficulty I had was deciding which injected mice displayed a sufficient percentage of effector memory T-cell population when compared to the controls. I found percentages of $1.26 \%$ and $2.68 \%$ to be sufficiently larger than the controls to warrant their use in the next islet transplant experiment. On the other hand, the two Marilyn mice with percentages of $0.76 \%$ and $0.59 \%$ were difficult to determine whether these mice were truly primed or not. Future statistical analysis of data with an 'unpaired t-test' did indeed show that the percentages between control and experimental groups was not significant. As well, even though histology did not show any T-cell infiltration, I did not have control groups to compare with the experimental mice.

With an experimental group deemed to be primed at the time. The next phase was to perform DBA-2 female islet transplants to both the primed Marilyn and Marilyn PD-1 $\mathrm{KO}$ mice.
Donor DBA/2NCR Islet Transplants Do Not Induce Transplant Rejection in Primed Marilyn and Marilyn PD-1 KO Recipient Mice

Due to no difference of both $\mathrm{CD} 69^{\mathrm{HI}} \mathrm{CD} 25^{\mathrm{HI}}$ and CD62 $\mathrm{L}^{\mathrm{LO}}$ CD44 ${ }^{\mathrm{HI}}$ cells in unprimed female Marilyn PD-1 KO, this experiment involved the use of Marilyn and Marilyn PD-1 $\mathrm{KO}$ mice primed by male ' $\mathrm{H}-\mathrm{Y}$ ' antigen. Having T-cell receptors specific for the male ' $\mathrm{H}-\mathrm{Y}$ ' antigen, this ensured

Figure 4. $A$, Primed female Marilyn and Marilyn PD-1 KO recipients received female DBA-2 islet transplants and were screened for activation markers (CD69H ${ }^{H}$ CD25 $\left.{ }^{H I}\right)$ and an effector memory T-cell population (CD62L L ${ }^{\mathrm{LO}} \mathrm{CD}_{4} 4^{\mathrm{H}}$ ) 11 days post-transplantation. Dot plot analyses were gated on TCR ${ }^{H}$ $\mathrm{CD} 4^{\mathrm{HI}}$. The average percent for activation markers (CD69 ${ }^{\text {HI }}$ CD25 ${ }^{\text {HI }}$ ) and effector memory T-cell populations (CD62L Lo $\mathrm{CD} 44^{\mathrm{H}}$ ) was calculated for female recipient Marilyn PD-1 KO $(n=1)$ and Marilyn $(n=2)$ mice. Percentages of control female Marilyn ( $n=1)$ and Marilyn PD-1 $\mathrm{KO}(\mathrm{n}=1)$ is shown (right). $B$, Blood glucose levels were taken periodically post-islet transplantation to monitor for signs of islet transplant rejection.

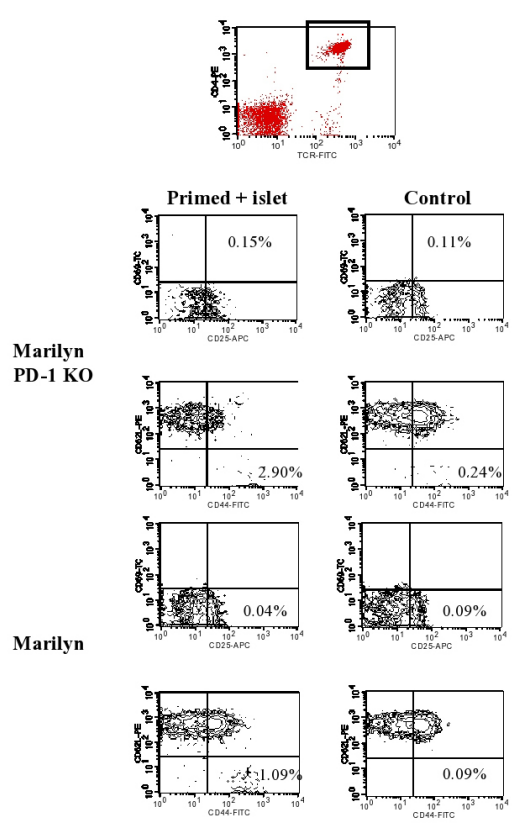

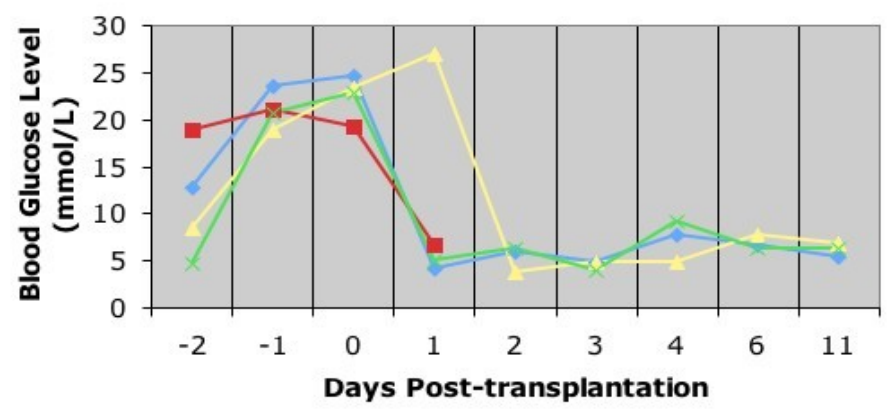
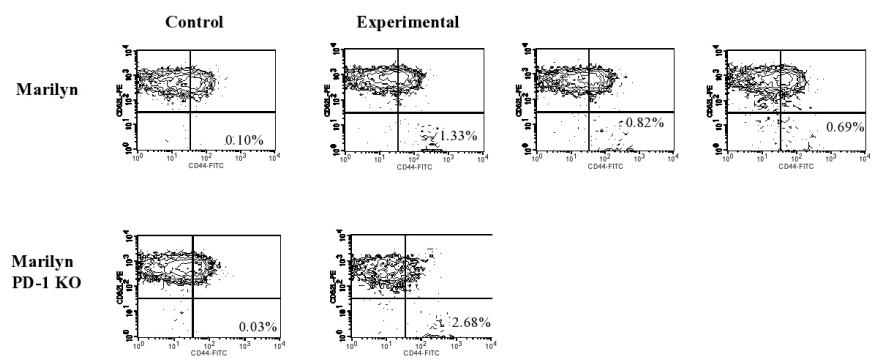

Figure 3. $A$, Female Marilyn mice $(n=3)$ were injected with $3 \times 10^{6} B 6$ male splenocytes. Representative plots show percent of effector memory T-cell population for control (left, $n=1$ ) and injected B6 male splenocytes (right) after 11 days IP injection. Female Marilyn PD-1 KO mice $(n=1)$ were injected with $3 \times 10^{6} \mathrm{~B} 6$ male splenocytes. Representative plots show percent of effector memory T-cell population for control (left, $n=1$ ) and injected B6 male splenocytes (right) after 11 days IP injection. 
that the priming process produced a sufficient number of memory effector T-cells that could be tested for islet rejection upon superantigen stimulation. Primed Marilyn and Marilyn PD-1 KO received DBA-2 islet transplants and were screened for activation markers (CD69 ${ }^{\mathrm{HI}}$ CD25 $\left.5^{\mathrm{HI}}\right)$ and an effector memory T-cell population (CD62L ${ }^{\mathrm{LO}} \mathrm{CD}^{\mathrm{C}} 4^{\mathrm{H}}$ ) 11 days post-transplantation.

Analysis of primed Marilyn recipient mice $(n=2)$ showed no large differences of activation markers $(0.04 \%)$ and effector memory T-cell populations (1.09\%) when compared with Marilyn control mouse $(n=1)$, which had $0.09 \%$ for both populations. Activation markers for primed Marilyn PD-1 KO mouse $(n=1)$ was $0.15 \%$ and this did not deviate far from control $(0.11 \%, n=1)$. On the other hand, effector memory T-cell populations for Marilyn PD-1 KO mouse $(n=1)$ had a slightly greater percentage $(2.90 \%)$ than control (0.24\%). Even with slight differences in effector memory populations for both experimental groups in comparison to control, primed recipient mice did not reject DBA-2 female islets, because blood glucose levels did never exceeded $15 \mathrm{mmol} / \mathrm{L}$.

\section{Discussion}

The main question asked in this research project was whether superantigens have a role in stimulating islet transplant rejection. The main conclusion reached is that superantigens do not mediate islet transplant rejection through CD4 T-cells, but the data obtained does not indicate as to what processes occur to induce tolerance of the DBA-2 superantigen.

Addressing this question involved asking three smaller questions: (1) if superantigens have the ability to stimulate monoclonal T-cell populations, (2) if superantigens have the ability to stimulate recipient naïve CD4 T-cells to result in transplant rejection, and (3) if superantigens have the ability to induce islet transplant rejection in primed recipient mice.

The first experiment involved culturing two different responder cells (female Marilyn PD-1 KO and female OT-2 mice) to different stimulator cells. This in vitro experiment did indeed show that female DBA-2 and BALB/c carrying superantigens could effectively stimulate proliferation of female Marilyn PD-1 KO and OT-2 monoclonal T-cell populations, respectively. This demonstrated that the OT-2 and $B A L B / c$ superantigens recognized the respective V $\beta$-chains of the Marilyn and OT-2 mice (V $\beta 6$ and V $\beta 5$, respectively). Proliferation data on female Marilyn mice were not successfully obtained and it would have been useful to compare proliferation rates between Marilyn and Marilyn PD-1 KO mice.

Recent research on superantigens has started to focus the role of $\mathrm{V} \alpha$-chains in being recognized by superantigens (23). As such, a useful future experiment would be to perform the same in vitro experiment (involving a V $\beta 6$ chain and DBA-2 superantigen) but with a different library of $\mathrm{V} \alpha$ chains. If there are significant differences in T-cell proliferation rates for some of the $\mathrm{Va}$ chains, then it may indicate a role of Va-chain and superantigen interaction. As well, mice carrying these Va-chains may subsequently be used in islet transplant experiments and see if rejection occurs.
The second experiment used female Marilyn PD-1 KO mice as recipients for female DBA-2 islet transplants. Presence effector markers were similar to that of control and recipients did not become diabetic. In the third experiment, Marilyn and Marilyn PD-1 KO mice primed with male ' $\mathrm{H}$ $Y^{\prime}$ ' antigen did not become diabetic when transplanted with female DBA-2 islets. Results obtained for activation markers were similar to unprimed recipients that were gated on $\mathrm{TCR}^{\mathrm{HI}} \mathrm{CD} 4^{\mathrm{HI}} \mathrm{T}$-cells. On the other hand, there was a slight increase (about 1-2\%) of effector memory T-cell populations in comparison to the control group.

Variable times of $\mathrm{T}$-cell proliferation by superantigens have been shown depending on MHC haplotype (24). In $\mathrm{H}-2^{\mathrm{b}}$ mice, for instance, peak proliferation generally occurred between days 6 and 8 (24). For MMTV, proliferation of T-cells peaked at 2 to 3 days (25). Because it is not well known how MHC haplotype will affect MMTV superantigen stimulated T-cell proliferation, screening for markers should be performed in the first ten days of transplantation. Data obtained on these two days could then be used to compare in later screenings to determine if: (1) T-cell populations actually proliferated in vivo in the first place, (suggesting clonal deletion in screenings 10 and 16 days post-transplantation) and (2) presence of activation markers if proliferation was present.

It is fairly established that superantigens have a propensity to stimulate polyclonal T-cell proliferation. The problem arises when addressing what particular effect this proliferation produces. Most of the research performed on superantigens has been done on the pyrogenic toxin superantigen family. This family includes the staphylococcal enterotoxins (SE)A through I (except F), staphylococcal toxic shock syndrome toxin-1 (TSST-1), streptococcal superantigen (SSA), and streptococcial pyrogenic exotoxins (SPE)A-C and -F $(26,27,28)$. In vivo studies performed with these pyrogenic toxins revealed $\mathrm{T}$-cells that become either anergic or deleted after proliferation. It is suggested that the fate of proliferated T-cells has more to do with what specific TCR V $\beta$-chain interacts with a particular superantigen (29). As well, other studies have explained that an in vivo response to superantigens gives rise to T-cells that are anergic if they survive deletion $(30,31,32)$.

Relating to the primed Marilyn and Marilyn PD-1 KO experiment, it is unknown whether the small presence of effector memory $\mathrm{T}$-cells in the primed recipient mice are anergic. To test if this population is anergic, effector memory T-cells from the primed recipient mice should be isolated and placed with two different stimulators: male ' $\mathrm{H}-\mathrm{Y}$ ' antigen and female DBA-2 superantigen. Another experiment that should be performed in the future is priming Marilyn and Marilyn mice with DBA-2 female mice prior to female DBA-2 islet transplantation.

Marilyn mice reject $\mathrm{B} 6$ male islet transplants due to having a T-cell receptor specific to only male ' $\mathrm{H}-\mathrm{Y}$ ' antigen (33). As such, it would also be useful to examine the effect of superantigen male islet transplants and see whether there would be faster, slower, or no rejection. 


\section{Acknowledgements}

I would like to thank Colin Anderson for letting me work in his lab and to obtain research experience under a wonderful working environment. I would also like to thank him for his intellectual guidance in my direct research topic. For all of my questions and troubleshooting I am grateful to Haide Razavy, Christa Smolarchuk, David Al-Adara, Catherine Ewen, and Raju Thangavelu.

\section{References:}

1. Cooper, M. D., and M. N. Alder. 2006. The evolution of adaptive immune systems. Cell 124: 815-822.

2. Hantash, B. M., L. Zhao, J. A. Knowles, and H.P. Lorenz. 2008. Adult and fetal wound healing. Front Biosci 13:51-61.

4. Holgate, S. T., and R. Polosa. 2008. Treatment strategies for allergy and asthma. Nat Rev. Immunol.

5. Brimkow, M. E., E. W. Jeffrey, K. A. Hjerrild, B. Paeper, L. B. Clark, S. A. Yasayko, J. E. Wilkinson, D. Galas, S. F. Ziegler, and F. Ramsdell. 2001. Disruption of a new forkhead/winged-helix protein, scurfin, results in the fatal lymphoproliferative disorder of the scurfy mouse. Nat Genet 27:68-73.

6. Lahl, K,. C. Loddenkemper, C. Drouin, J. Freyer, J. Arnason, G. Eberl, A. Hamann, H. Wagner, J. Huehn, and T. Sparwasser. 2007. Selective depletion of Foxp3+ regulatory $T$ cells induces a scurfy-like disease. J Exp Med 204:57-63.

7. Roopenian, Derry; Choi, Evan Young; Brown, Aaron. Immunological Reviews, Dec2002, Vol. 190 Issue 1, p86.

8. Borghesi, L., and C. Milcarek. 2007. Innate versus adaptive immunity: a paradigm past its prime? Cancer Res 67:3989-3993.

9. Sagerstrom, C.G., E. M. Kerr, J. P. Allison and M. M. Davis. 1993. Activation and differentiation requirements of primary T cells in vitro. Proc Natl Acad Sci U S A 90:89878991.

10. Felix, N. J., and P. M. Allen. 2007. Specificity of T-cell alloreactivity. Nat Rev Immunol 7:942-953.

11. Stefanová, I., Dorfman, J., \& Germain, R. (2002). Self-recognition promotes the foreign antigen sensitivity of naive T lymphocytes. Nature, 420(6914), 429.

12. Jensen, P. (2007). Recent advances in antigen processing and presentation. Nature Immunology, 8(10), 1041-1048.

13. Gras, S., Kjer-Nielsen, L., Burrows, S., McCluskey, J., \& Rossjohn, J. (2008). T-cell receptor bias and immunity. Current Opinion in Immunology, 20(1), 119-125.

14. Burnet, F. M. 1959. The Clonal Selection Theory of Acquired Immunity. Vanderbilt University Press, Nashville, TN.

15. Conrad, B., \& Weissmahr, R. (1997). A human endogenous retroviral superantigen as candidate autoimmune gene in type I diabetes. Cell, 90(2), 303.

16. Gould, D., \& Auchincloss, H. (1999). Direct and indirect recognition: the role of $\mathrm{MHC}$ antigens in graft rejection. Immunology Today, 20(2), 77-82.

17. Li, H., Llera, A., Malchiodi, E., \& Mariuzza, R. (1999). THE STRUCTURAL BASIS OF T CELL ACTIVATION BY SUPERANTIGENS. Annual Review of Immunology, 17(1),
435.

18. Olivera J. F., L., A., Debruyne, \& Bishop K., D. (1996). T Cell Receptor (TCR) Repertoire in Alloimune Responses. Intern Rev. Immunol. 13, 187-207.

19. Cauley, L., Miller, E., Yen, M., \& Swain, S. (2000). Superantigen-induced CD4 T cell tolerance mediated by myeloid cells and IFN-gamma. Journal Of Immunology (Baltimore, Md.: 1950), 165(11), 6056-6066.

20. Sicat, J., Sutkowski, N., \& Huber, B. (2005). Expression of human endogenous retrovirus HERV-K18 superantigen is elevated in juvenile rheumatoid arthritis. Journal of Rheumatology, 32(9), 1821-1831.

21. Lizhe, X., Zhiwei, S., Linsheng, G., Fodera, B., Keogh, A., Joplin, R., et al. (2003). Does a betaretrovirus infection trigger primary biliary cirrhosis?. Proceedings of the National Academy of Sciences of the United States of America, 100(14), 8454.

22. Luther, S., A., \& Acha-Orbea, H. (1996). Immune response to mouse mammary tumor virus. Current Opinion in Immunology, 8(4), 498-502.

23. Pumphrey, N., Vuidepot, A., Jakobsen, B., Forsberg, G., Walse, B., \& Lindkvist-Petersson, K. (2007). Cutting edge: Evidence of direct TCR alpha-chain interaction with superantigen. Journal Of Immunology (Baltimore, Md.: 1950), 179(5), 2700-2704.

24. Hayden, K., Tough, D., \& Webb, S. (1996). In vivo response of mature $\mathrm{T}$ cells to Mlsa antigens. Longterm progeny of dividing cells include cells with a naive phenotype. Journal Of Immunology (Baltimore, Md.: 1950), 156(1), 48-55.

25. Acha-Orbea, H., \& MacDonald, H. (1995). Superantigens of mouse mammary tumor virus. Annual Review Of Immunology, 13459-486.

26. Bohach G., A., Fast D.J., Nelson R., D., Schlievert, P., M. 1990. Staphylococcal and streptococcal pyrogenic toxins involved in toxic shock syndrome and related illnesses. Crit. Rev. Microbiol. 17:251-272.

27. Betley M., J., Borst D., W., Regassa L., B. 1992. Staphylococcal enterotoxins, toxic shock syndrome toxin and streptococcal pyrogenic exotoxins: a comparative study of their molecular biology. Chem. Immunol. 55:1-35.

28. Bohach, G., A. 1997. Staphylococcal enterotoxins B and C. In Superantigens: Molecular Biology, Immunology and Relevance to Humans Disease, ed. DYM Leung, BT Huber, PM Schlievert, Marcel Dekker Inc. NY, pp. 167-198.

29. Rellahan, B. L., Jones, L. A. Kruisbeek, A. M., Fry, A. M. \& Matis, L. A. 1990. In vivo induction of anergy in peripheral ${\mathrm{V} \beta 8^{+}}^{+} \mathrm{T}$ cells by staphylococcal enterotoxin $\mathrm{B}$. J. Exp. Med. 172:1091.

30. Sundstedt, A., Holden, I., Hansson, J., Hedlund, G., Kalland, T. and Dohlsten, M. 1995. Superantigen-induced anergy in cytotoxic CD8 ${ }^{+}$T cells. J. Immunol. 154:6306.

32. Macdonald, H. R., Baschieri, S. and Lees, R. K. 1991. Clonal expansion precedes anergy and death of $\mathrm{V} \beta 8^{+}$ peripheral $T$ cells responding to staphylococcal enterotoxin B in vivo. Euro. J. Immunol. 21:1963.

33. Chan, W., Razavy, H., \& Anderson, C. (2008). Differential susceptibility of allogeneic targets to indirect CD4 immunity generates split tolerance. Journal Of Immunology (Baltimore, Md.: 1950), 181(7), 4603-4612. 